\title{
Influence of sternal size and inadvertent paramedian sternotomy on stability of the closure site: A clinical and mechanical study
}

\author{
J. Zeitani, MD, PhD, ${ }^{a}$ A. Penta de Peppo, MD, ${ }^{b}$ M. Moscarelli, MD, ${ }^{a}$ L. Guerrieri Wolf, MD, ${ }^{a}$ A. Scafuri, MD, ${ }^{a}$
}

P. Nardi, MD, ${ }^{a}$ F. Nanni, PhD, ${ }^{c}$ E. Di Marzio, MD, ${ }^{d}$ P. De Vico, MD, ${ }^{d}$ and L. Chiariello, MD ${ }^{a}$

From the Departments of Cardiac Surgery ${ }^{\mathrm{a}}$ and Clinical Technology ${ }^{\mathrm{c}}$ and the Division of Anaesthesiology, ${ }^{\mathrm{d}}$ Tor Vergata University, Rome, Italy, and the Department of Cardiac Surgery, ${ }^{\mathrm{b}}$ 2nd University of Naples, Naples, Italy.

Received for publication Dec 2, 2005; revisions received Feb 16, 2006; accepted for publication March 8, 2006.

Address for reprints: Jacob Zeitani, MD, Division of Cardiac Surgery, Tor Vergata University, Via Oxford 85, 00133 Rome, Italy (E-mail: zeitani@hotmail.com).

J Thorac Cardiovasc Surg 2006;132:38-42

$0022-5223 / \$ 32.00$

Copyright $\odot 2006$ by The American Association for Thoracic Surgery

doi:10.1016/j.jtcvs.2006.03.015
Background: The influence of sternal size and of inadvertent paramedian sternotomy on stability of the closure site is not well defined.

Methods: Data on 171 consecutive patients undergoing cardiac surgery through a midline sternotomy were prospectively collected. Intraoperative measurements of sternal dimension included thickness and width at the manubrium, the third and fifth intercostal spaces; paramedian sternotomy was defined as width of one side of the sternum equaling $75 \%$ or more of the entire width, at any of the three levels. The chest was closed with simple peristernal steel wires and inspected to detect deep wound infection and/or instability for 3 postoperative months. The sternal factors and several patient/surgery-related factors were included in a multivariate analysis model to identify factors affecting stability. An electromechanical traction test was conducted on 6 rewired sternal models after midline or paramedian sternotomy and separation data were analyzed.

Results: Chest instability was detected in $12(7 \%)$ patients and wound infection in $2(1.2 \%)$. Patient weight $(P=.03)$, depressed left ventricular function $(P=.04)$, sternum thickness (indexed to body weight, $P=.03$ ), and paramedian sternotomy $(P=.0001)$ were risk factors of postoperative instability; paramedian sternotomy was the only independent predictor $(P=.001)$. The electromechanical test showed more lateral displacement of the two rewired sternal halves after paramedian than midline sternotomy $(P=.002)$; accordingly, load at fracture point was lower after paramedian sternotomy $(220 \pm 20 \mathrm{~N}$ vs $545 \pm 25 \mathrm{~N}, P=0.001)$.

Conclusions: Inadvertent paramedian sternomoty strongly affects postoperative chest wound stability independently from sternal size, requiring prompt reinforcement of chest closure.

$\mathrm{M}$ idline sternotomy, introduced by Julian and associates ${ }^{1}$ in 1957, is the preferred access for operations on the heart and great vessels, allowing good surgical exposure and rapid postoperative wound healing. Nevertheless, wound complications may occur, particularly in patients with concomitant pathologic conditions affecting wound healing, such as chronic obstructive pulmonary disease, diabetes, obesity, or peripheral arterial disease, or after extensive sternal devascularization owing to bilateral internal thoracic artery harvesting. ${ }^{2-8}$ Deep wound dehiscence and consequent instability of the chest closure undoubtedly represents the most feared complication, facilitating tissue infection and mediastinitis. ${ }^{9,10}$ Reinforcement of the chest closure, as proposed with different techniques by Robicsek, Daugherty, and Cook ${ }^{11}$ and by other authors, ${ }^{12,13}$ may prevent postoperative dehiscence in patients at high risk of wound complications; also, titanium plates, ${ }^{14}$ stainless steel coils, or cables ${ }^{15,16}$ have been proposed in substitution of simple steel wires and have been tested to improve postoperative sternal stability. 
TABLE 1. Clinical characteristics of patients with and without postoperative instability of the chest closure site

\begin{tabular}{lccc}
\hline Variables & $\begin{array}{c}\text { Instability } \\
\text { (n = 12) }\end{array}$ & $\begin{array}{c}\text { Stability } \\
(\mathbf{n}=\mathbf{1 5 9 )}\end{array}$ & $\boldsymbol{P}$ value \\
\hline Age (y) & $68.3 \pm 6.1$ & $66.5 \pm 10.2$ & .58 \\
Age $>70$ y & $7(58 \%)$ & $65(41 \%)$ & .23 \\
Sex (M/F) & $7 / 5$ & $108 / 51$ & .49 \\
Diabetes mellitus & $4(33 \%)$ & $44(28 \%)$ & .67 \\
COPD & $4(33 \%)$ & $45(28 \%)$ & .71 \\
Renal dysfunction & $1(8 \%)$ & $23(14 \%)$ & .55 \\
LVEF $<50 \%$ & $5(42 \%)$ & $28(18 \%)$ & .04 \\
Weight (kg) & $82.4 \pm 10.5$ & $73.8 \pm 13.3$ & .03 \\
Weight $>80 \mathrm{~kg}$ & $7(58 \%)$ & $45(28 \%)$ & .03 \\
Obesity* & $5(42 \%)$ & $36(23 \%)$ & .13 \\
CABG procedure & $8(67 \%)$ & $91(57 \%)$ & .52 \\
BITA use & $4(33 \%)$ & $43(27 \%)$ & .63 \\
CPB time (min) & $89 \pm 25$ & $77 \pm 28$ & .20 \\
Use of inotropic drugs & $6(50 \%)$ & $44(28 \%)$ & .10 \\
Transfusion of blood units & $8(67 \%)$ & $101(63 \%)$ & .82 \\
\hline
\end{tabular}

COPD, Chronic obstructive pulmonary disease; $\angle V E F$, left ventricular ejection fraction; $C A B G$, coronary artery bypass grafting; $B I T A$, bilateral internal thoracic artery; $C P B$, cardiopulmonary bypass. *Obesity is defined as body mass index (weight/height ${ }^{2}$ ) $>30.0$.

Indeed, routine application of time-consuming techniques and/or costly materials depends on the precise identification of patients who would clearly benefit from reinforcement of the chest closure. Despite the numerous reports on several risk factors of wound complications, the influence of sternum-related variables in comparison with the other factors has been poorly investigated. The purpose of this study was to analyze the impact of size of the sternum and inadvertent performance of a paramedian sternotomy on stability of the closure site.

\section{Methods}

From June 2004 to November 2004, data on 171 consecutive patients undergoing median sternotomy for coronary artery bypass grafting $(\mathrm{n}=99)$ or valve replacement $(\mathrm{n}=72)$ at our institution were prospectively collected. Also, a laboratory electromechanical test was conducted on 6 sternal models to simulate influence of inadvertent paramedian sternotomy on resistance of the rewired sternum to lateral distraction forces.

Preoperative and intraoperative characteristics of patients are shown in Table 1. Patients undergoing primary reinforcement of the closure site were not included in the study. In coronary patients, bilateral internal thoracic arteries were harvested in a skeletonized fashion. After skin disinfection with $10 \%$ povidoneiodine (Betadine) solution and intravenous antibiotic prophylaxis with $2 \mathrm{~g}$ of ceftizoxime, sternotomy was performed with an oscillating saw. Sternal measurements were taken at the end of the surgical procedure, before closure of the chest: width and thickness of the two sternal halves were measured with a sterile calibrated ruler at the manubrium, the third and fifth intercostal spaces. Full bone width at the three levels was obtained by addition of mea- surements of the two halves; the average individual sternal width and thickness were then determined for each patient. Sternal measurements were also indexed to the patient's body weight. Paramedian sternotomy was defined as width of one side of the sternum equaling $75 \%$ or more of the full sternum width, at any of the three measurement levels. Reapproximation of the sternum was then achieved by 6 to 10 (approximately 1 for each $10 \mathrm{~kg}$ of patient weight) single interrupted stainless steel wires, 2 to 3 through the manubrium and the others in the peristernal position at the intercostal spaces. The fascia and the subcutaneous layers were routinely closed with 2 continuous absorbable $0-0$ polyglycolic acid suture lines, and the skin was closed with an intradermic absorbable 4-0 polyglycolic acid suture line. Instability of chest closure was defined as instability of the two rewired halves detected at palpation over the sternum during a brief alternating arm extension exercise; additional deep wound infection was diagnosed, according to the "Guideline for Prevention of Surgical Site Infection" of the Hospital Infection Control Practices Committee, ${ }^{17}$ in case of visual evidence of mediastinitis, isolation of an organism from culture of mediastinal tissue or fluid, fever, or instability of the sternum associated with purulent drainage from the mediastinum.

The sternotomy site was inspected monthly for 3 months after discharge from the hospital. Follow-up was $100 \%$ complete.

\section{Electromechanical Test}

The electromechanical test was conducted on 6 artificial sternal models formed from $20 \mathrm{lb} / \mathrm{ft}^{3}$-density polyurethane foam (Pacific Research Labs, Inc, Vashon Island, Wash), a material that has been characterized as a model for human cancellous bone ${ }^{18}$ and used to construct sternal models, which have been validated for studies of closure methods ${ }^{19}$ and are widely adopted in electromechanical studies. ${ }^{14,16}$ The models were longitudinally divided at the midline $(\mathrm{n}=3)$ or at the paramedian $(75 \%$ asymmetrical $)$ line $(\mathrm{n}=3)$ with an oscillating saw, rewired by a cardiothoracic surgeon with 5 peristernal No. 5 steel wires (AE Medical Corporation, Farmingdale, $\mathrm{NJ}$ ) placed in simple interrupted fashion, and then mounted onto an electromechanical testing system (model 8055; Instron Corp, Canton, Mass) (Figure 1). In particular, 6 lateral anchoring holes were made in each side of the sterna, 5 at the costal junctions and 1 in the manubrium, and lateral distraction forces were applied through pairs of steel cables secured across the holes through small metal hoses. Three strain gauges (Vishay Intertecnology Inc, Malvern, Pa) were applied over the closure line on the posterior surface of the manubrium, midsternum (at the third intercostal space), and xiphoid, and separation of the two sternal halves was measured with a Spider 8 apparatus in half-bridge configuration (HBM, Marlborough, Mass) during a continuously increasing tensile test at $2 \mathrm{~mm} / \mathrm{min}$, to generate a load-displacement curve until the construct would break.

\section{Statistical Analysis}

Influence of variables on stability of the closure site was assessed by the unpaired Student $t$ test, the $\chi^{2}$ test, or the Fisher exact test, as appropriate. Sternum-related risk factors included sternal width and thickness at the three sternal levels, the mean individual patient width and thickness, and occurrence of inadvertent paramedian sternotomy. Other patient- and surgery-related factors included age, sex, New York Heart Association functional class 


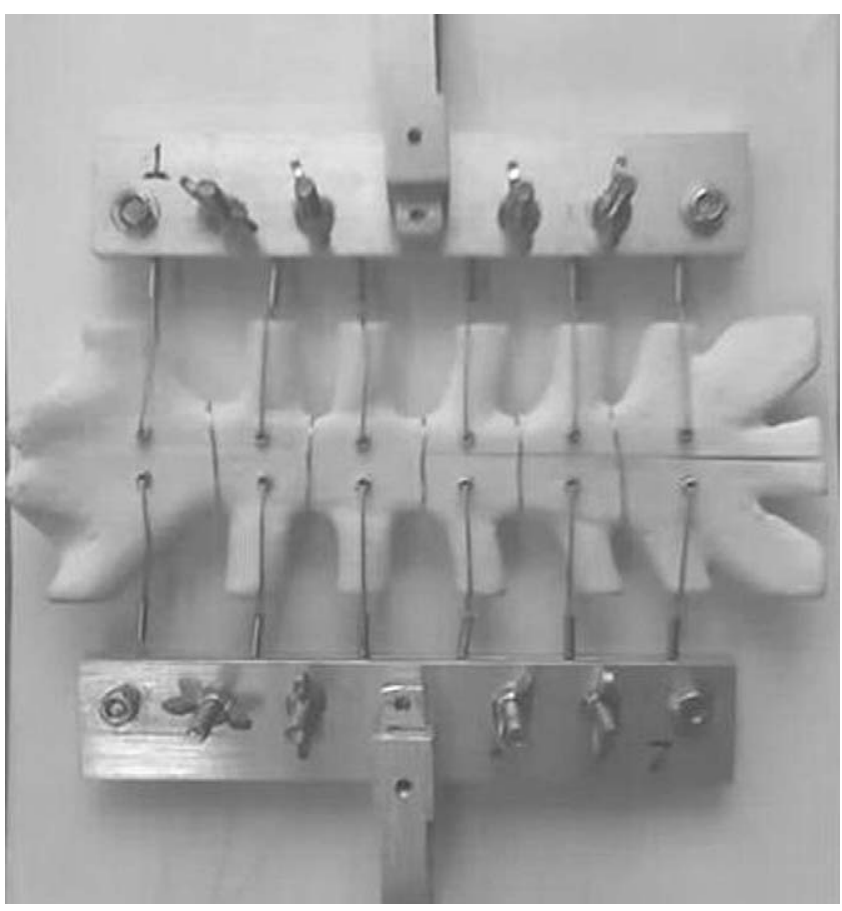

Figure 1. Photograph of the electromechanical testing system providing lateral distraction forces to the anchoring points on the rewired polyurethane sternal model.

III-IV, patient weight as a continuous variable and as weight greater than $80 \mathrm{~kg}$, obesity (body mass index $\geq 30 \mathrm{~kg} / \mathrm{m}^{2}$ ), echocardiographic left ventricular ejection fraction lower than $50 \%$, diabetes mellitus, chronic obstructive pulmonary disease, peripheral vascular disease, renal failure (serum creatinine value $>$ $1.5 \mathrm{mg} / \mathrm{dL}$ ), type of surgical procedure (bypass grafting or valve replacement), resident or attending surgeon, bilateral internal thoracic artery harvesting, time of cardiopulmonary bypass, postoperative use of inotropic drugs during the intensive care stay, reopening for bleeding, and transfusion of blood units. Factors with a probability $(P)$ value less than .1 were then included in a stepwise logistic regression prediction model.

Separation data of the electromechanical test were compared by 2-way repeated-measures analysis of variance to detect influence of type of sternotomy and increasing loads on lateral displacement of sternal halves. Ultimate load values at the time of fracture of the sternal models were compared by the unpaired Student's $t$ test. Variables are presented as mean \pm 1 standard deviation. Statistical analysis was done by the SPSS statistical software package (SPSS Inc, Chicago, IL).

\section{Results}

No hospital mortality occurred. Instability of the chest closure was detected in $12(7 \%)$ patients; wound infection was diagnosed in $2(1.2 \%)$ patients. Surgical treatment included chest reopening, debridement of nectrotic tissue, rewiring of the sternum according to the Robicsek method ${ }^{11}$ in 3 pa-
TABLE 2. Sternum-related variables in patients with and without postoperative instability of the chest closure site

\begin{tabular}{|c|c|c|c|}
\hline Variable & $\begin{array}{l}\text { Instability } \\
(\mathrm{n}=12)\end{array}$ & $\begin{array}{l}\text { Stability } \\
(\mathrm{n}=159)\end{array}$ & $\begin{array}{c}P \\
\text { value }\end{array}$ \\
\hline Sternum width, mean (mm) & $36.1 \pm 6.5$ & $32.9 \pm 5.8$ & .09 \\
\hline $\begin{array}{l}\text { Sternum width/body weight } \\
(\mathrm{mm} / \mathrm{kg})\end{array}$ & $0.43 \pm 0.07$ & $0.46 \pm 0.11$ & .49 \\
\hline Sternum thickness, mean $(\mathrm{mm})$ & $10.8 \pm 1.4$ & $11.2 \pm 2.2$ & .48 \\
\hline $\begin{array}{l}\text { Sternum thickness/body } \\
\text { weight }(\mathrm{mm} / \mathrm{kg})\end{array}$ & $0.13 \pm 0.03$ & $0.16 \pm 0.03$ & .03 \\
\hline Paramedian sternotomy & $6(50 \%)$ & $10(6.2 \%)$ & .0001 \\
\hline
\end{tabular}

tients or with plain steel wires in 5 patients, or sternal reapproximation by use of bilateral "pectoralis major" muscle flaps in 4 patients; primary closure of subcutaneous and skin layers was then accomplished by absorbable sutures, as previously reported in patients with superficial wound dehiscence,$^{20}$ and wide-spectrum intravenous antibiotic therapy was instituted. All patients recovered completely. At univariate analysis, significant predictors of instability included patient body weight $(P=.03)$, body weight greater than $80 \mathrm{~kg}(P=.03)$, preoperative depressed left ventricular function $(P=.04)$, the mean individual sternal thickness indexed to patient's body weight $(P=.03)$, and inadvertent paramedian sternotomy $(P=.0001)$; no other measurement of sternal size was related to wound instability (Tables 1 and 2). At multivariate analysis, the paramedian sternotomy was the only risk factor affecting stability of the closure site, independently of the other variables $(P=.001$, odds ratio 11.4, 95\% confidence limits 2.5-51.7). All surgeons were right-handed: paramedian sternotomy occurred to the right in $11(69 \%)$ and to the left in $5(31 \%)$ patients; correlation of the paramedian incision with the side on which the internal thoracic artery was mobilized did not increase the chance of wound instability, which occurred in 2 of $6(33 \%)$ patients with correlation and in 4 of $10(40 \%)$ of the other patients. No patient- or surgeon-related factor influencing occurrence of the off-center incision could be identified, including patient sex $(P=.67)$, weight $(P=.32)$, obesity $(P=.18)$, sternal width $(P=.16)$ and thickness $(P=.81)$, or resident or attending surgeon $(P=.27)$.

All traction tests were interrupted for transverse fracture of one of the two halves of the rewired sternal models, at the sternoxiphoid junction in 5 and the lower third in 1; breakage of the construct occurred after steel wires cut through the casts for a variable extent. Ultimate load values inducing fracture were lower after paramedian sternotomy $(220 \pm 20$ $\mathrm{N}$ vs $545 \pm 25 \mathrm{~N}, P=.001)$. Lateral displacement at 200 $\mathrm{N}$ tensile force (shortly before fracture) after median or paramedian sternotomy was $9.5 \pm 0.4$ versus $11.2 \pm 0.8$ $\mathrm{mm}$ at the xiphoid $(P=.016), 1.5 \pm 0.3$ versus $2.7 \pm 0.4$ $\mathrm{mm}$ at the midsternum $(P=.008)$, and $3.8 \pm 0.6$ versus 4.7 


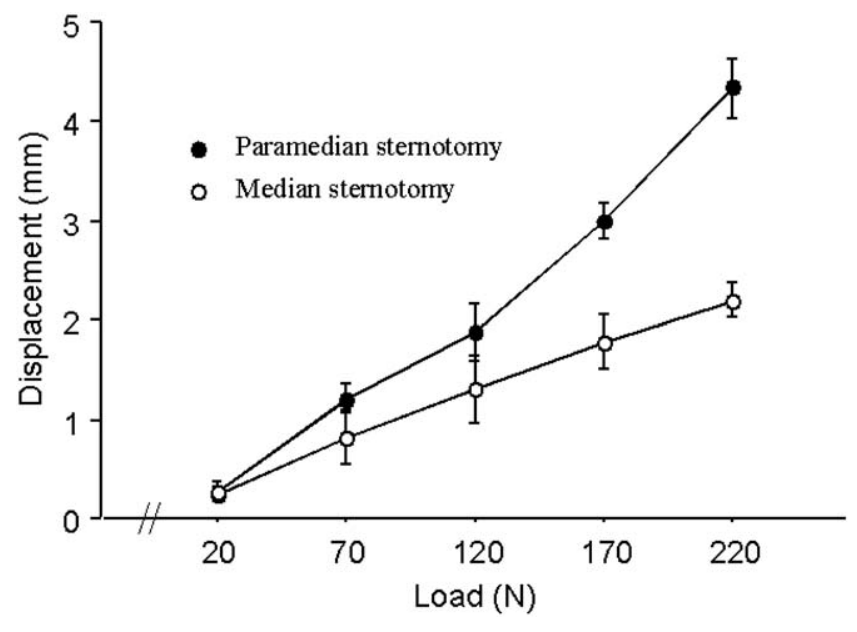

Figure 2. Separation data of the rewired sternal models after midline ( $\mathrm{n}=3$ ) or paramedian ( $\mathrm{n}=3$ ) sternotomy, up to forces causing fracture. Displacement differs significantly from other group $(P=.02)$. Fracture occurred earlier in models divided by paramedian sternotomy $(220 \pm 20 \mathrm{~N}$ vs $545 \pm 25 \mathrm{~N}, P=.001)$.

$\pm 0.5 \mathrm{~mm}$ at the manubrium $(P=.1)$. Comparison between mean lateral displacement of sternal halves during traction at increasing loads showed significantly more separation after paramedian than midline sternotomy $(P=.002)$ (Figure 2).

\section{Discussion}

Midline sternotomy is widely used in cardiac surgery, providing prompt access and good surgical exposure at low risk of postoperative wound complications; moreover, sternal closure can be accomplished quickly and efficiently by reapproximation of the two sternal halves with inexpensive simple steel wires. Nevertheless, postoperative sternal instability occurs in some patients, causing deep wound dehiscence and favoring mediastinitis, the most serious wound complication, still producing high morbidity and mortality in up to $2 \%$ of patients after cardiac surgery. ${ }^{9,10}$ Several studies focus on the influence of concomitant pathologic conditions and of surgery-related factors on wound healing: advanced cardiac disease, diabetes, peripheral vascular disease, smoking, and bilateral internal thoracic artery harvesting are known risk factors. ${ }^{2-8,21}$ Also, factors increasing forces acting on the sternum, such as patient overweight, chronic obstructive pulmonary disease, and prolonged mechanical ventilation, have been frequently related to an increased risk of wound complications. ${ }^{2,3}$ Accordingly, different techniques and materials have been proposed to enhance stability of sternal closure in high-risk patients. ${ }^{11-16}$ Interestingly, the impact of the anatomic characteristics of the sternum on wound complications has been poorly investigated; also, the precise influence of inadvertent para- median sternotomy, a technical drawback of longitudinal chest opening, has not been well defined in comparison with other known risk factors of wound complications. We hypothesized that a better knowledge of these aspects might also help to clearly identify those patients who would benefit from routine application of a reinforcement technique of chest closure. Indeed, the various techniques and materials for sternum reinforcement are somewhat time-consuming and more expensive than the usual closure with simple wires, and surgeons may hesitate to adopt routinely one of these techniques in all categories of patients at risk.

We found that sternal size did not independently affect chest wound stability; in fact, sternal thickness affected postoperative stability if indexed to the patient's body weight, which is a widely known risk factor for wound complications. That finding is presumably related to the great variability of sternal width and thickness that is normal between patients. We found, instead, that inadvertent performance of paramedian sternotomy strongly affected postoperative stability at the closure site, as also suggested previously. ${ }^{22}$ As expected, other known risk factors of deep wound dehiscence were identified, such as patient weight and depressed left ventricular function. Interestingly, at multivariate comparisons, paramedian sternotomy was the most powerful risk factor of postoperative chest instability, suggesting that this technical drawback might be as important as or more important than other already widely known risk factors; of note, that influence occurred independently of sternal size and the other analyzed variables. That finding was enhanced by the observations at the electromechanical test on the rewired sternal models, showing more separation of the two sternal halves during lateral traction and a consistently lower ultimate load inducing the model break after paramedian than midline sternotomy. As already shown in previous reports, ${ }^{14-16}$ the higher lateral displacement was detected at the xiphoid.

These findings have practical implications on the intraoperative choice of the method of chest closure; indeed, occurrence of inadvertent paramedian sternotomy is easily identified by inspection at the time of chest opening and may therefore promptly suggest reinforcement of chest closure by use of one of the proposed methods. Imperfect sternal opening may not simply depend on surgical skill and experience; for instance, we found the same impact of residents versus attending surgeons on the occurrence of sternal instability, as already reported by others. ${ }^{23}$ Also, precise sawing at the midline may easily be compromised if the outer sternal border is hardly detectable, as in overweight patients, or when the bone is narrow; nonetheless, patients significantly at risk for a paramedian incision could not be identified in the present study.

In conclusion, occurrence of inadvertent paramedian sternotomy, independently of sternal size or other factors, 
appears highly significant among factors jeopardizing a successful chest closure and may promptly induce surgeons to routine application of a sternal reinforcement technique.

\section{References}

1. Julian OC, Lopez-Belio M, Dye WS, Javid H, Grove WJ. The median sternal incision in intracardiac surgery with extracorporeal circulation: a general evolution of its use in heart surgery. Surgery. 1957;42:75361.

2. The Parisian Mediastinitis Study Group. Risk factors for deep sternal wound infection after sternotomy: a prospective multicenter study. J Thorac Cardiovasc Surg. 1996;111:1200-7.

3. Ridderstolpe L, Gill H, Granfeldt H, Ahlfeldt H, Rutberg H. Superficial and deep sternal wound complications: incidence, risk factors and mortality. Eur J Cardiothorac Surg. 2001;20:1168-75.

4. Loop FD, Lytle BW, Cosgrove DM, Mahfood S, McHenry MC, Goormastic M, et al. Sternal wound complications after isolated coronary artery bypass grafting: early and late mortality, morbidity, and cost of care. Ann Thorac Surg. 1990;49:179-87.

5. Kouchoukos NT, Wareing TH, Murphy SF, Pelate C, Marshall WG. Risks of bilateral internal mammary artery bypass grafting. Ann Thorac Surg. 1990;49:210-9.

6. Jonkers D, Elenbaas T, Terporten P, Nieman F, Stobberingh E. Prevalence of 90-days postoperative wound infections after cardiac surgery. Eur J Cardiothorac Surg. 2003;23:97-102.

7. De Paulis R, de Notaris S, Scaffa R, Nardella S, Zeitani J, Del Giudice $\mathrm{C}$, et al. The effect of bilateral internal thoracic artery harvesting on superficial and deep sternal infection: the role of skeletonization. J Thorac Cardiovasc Surg. 2005;129:536-43.

8. Seyfer AE, Shriver CD, Miller GM, Graeber GM. Sternal blood flow after median sternotomy and mobilization of the internal mammary arteries. Surgery. 1988;104:899-904.

9. El Oakley RM, Wright JE. Postoperative mediastinitis: classification and management. Ann Thorac Surg. 1996;61:1030-6.

10. Bitkover CY, Gardlund B. Mediastinitis after cardiovascular operations: a case-control study of risk factors. Ann Thorac Surg. 1998;65: $36-40$.
11. Robicsek F, Daugherty HK, Cook JW. The prevention and treatment of sternum separation following open heart surgery. $J$ Thorac Cardiovasc Surg. 1977;73:267-8.

12. Chlosta WF, Elefteriades JA. Simplified method of reinforced sternal closure. Ann Thorac Surg. 1995;60:1428-9.

13. Al Ebrahim K. Reinforced sternal closure: the bilateral straight longitudinal wire technique. Asian Cardiovasc Thorac Ann. 2003;11:90-1.

14. Pai S, Gunja NJ, Dupak EL, McMahon NL, Roth TR, Lalikos JF, et al In vitro comparison of wire and plate fixation for midline sternotomies. Ann Thorac Surg. 2005;80:962-8.

15. McGregor WE, Payne M, Trimble DR, Farkas KM, Magovern JA Improvement of sternal closure stability with reinforced steel wires. Ann Thorac Surg. 2003;76:1631-4.

16. Cohen DJ, Griffin LV. A biomedical comparison of three sternotomy closure techniques. Ann Thorac Surg. 2002;73:563-8.

17. Mangram AJ, Horan TC, Pearson ML, Silver LC, Jarvis WR. Guideline for prevention of surgical site infection, 1999. Hospital Infection Control Practices Advisory Committee. Infect Control Hosp Epidemiol. 1999;20:250-78.

18. Szivek JA, Thomas M, Benjamin JB. Characterization of a synthetic foam as a model for human cancellous bone. J Appl Biomater. 1993; 4:269-72.

19. Trumble DR, McGregor WE, Magovern JA. Validation of a bone analog model for studies of sternal closure. Ann Thorac Surg 2002; 74:739-44

20. Zeitani J, Bertoldo F, Bassano C, Penta de Peppo A, Pellegrino A, El Fakhri FM, et al. Superficial wound dehiscence after median sternotomy: surgical treatment versus secondary wound healing. Ann Thorac Surg. 2004;77:672-5.

21. Peivandi AA, Kasper-Konig W, Quinkenstein E, Loos AH, Dahm M. Risk factors influencing the outcome after surgical treatment of complicated deep sternal wound complications. Cardiovasc Surg. 2003; 11:207-12.

22. Shafir R, Weiss J, Herman O, Cohen N, Stern D, Igra Y. Faulty sternotomy and complications after median sternotomy. $J$ Thorac Cardiovasc Surg. 1988;96:310-3.

23. Breyer RH, Mills SA, Hudspeth AS, Johnston FR, Cordell AR. A prospective study of sternal wound complications. Ann Thorac Surg.1984;37:412-6. 